\title{
Growth regulators influence on stability of shoots and ascorbic acid content at cadmium and nickel joint action
}

\author{
T. A. Artiushenko - V. M. Grishko \\ Kryvyi Rig Botanic Garden of the National Academy of Sciences of Ukraine \\ Plant Physiology and Soil Biology Department, Kryvyi Rig, Ukraine \\ vit.grishko@rambler.ru
}

\begin{abstract}
SUMMARY
It is shown that for a maize the most effective protector of cadmium and nickel influence was zeastimulin, for a pea - agrostimulin. A protective function of emistim $C$ for both cultures was insignificant. It is set that zeastimulin is influential in the increased metals absorption of a root system, however substantially (on 15\% for a nickel and twice for a cadmium) reduces their translocation to above-ground part of plants. Previous treatment of pea seed by agristimulin also intensified the accumulation of nickel roots on $60 \%$ and did not influence on cadmium absorption and toxicants translocation to tissues of assimilatory organs. The protector role of growth regulators to cadmium and nickel joint influence shows up in the increase of ascorbic acid maintenance in the roots cells of both species to 34\%, where as in leaves - at a maize resulted in the lowering of vitamin C amount (on 28\%), but at a pea-increase on $20 \%$.
\end{abstract}

Keywords: maize, pea, cadmium, nickel, stress, growth regulators, ascorbic acid

\section{INTRODUCTION}

In science literature of the last years much attention spared the questions of plants tolerance to the various unfavorable factors of environment. In particular, the special scientific and practical interest causes research of plants metaltolerance, in a that number at the complex contamination conditions (Pignocchi et al., 2007; Bartoli et al., 2009). One of the earliest symptoms of unfavorable heavy metals action there is plants growth braking. The plants roots come forward the first target and at the same time powerful barrier on the way of pollutants transport to above-ground organs. Therefore important role in finding out of degree of metaltolerance can play the methods of estimation of influence of metals on rootage growth (Wilkins, 1978; Pignocchi et al., 2007).

Together with it acquires actuality the question of search of ways and facilities of plants adaptation ability increase at the contamination conditions. In a modern plant-grower to that aim widely apply the growth regulators, which combine in itself growth stimulate and antistress action in relation to the different by character environment unfavorable factors. Numerous researches are rotin the protector role of separate plants growth regulators at the drought (Nyzhnyk et al., 2004), high temperatures, contamination heavy metals, and other. However much possibility of the growth regulators use for the heavy metals toxicness decline until now remains studied not in a complete measure (Shigeoka et al., 2003). Therefore the purpose of our research was a biotesting of cadmium and nickel joint action and efficiency of the use of plants growth regulators for the metals negative influence decline.

\section{MATERIAL AND METHODS}

The researches objects were maize shoots (Zea mays L.) of hybrids Blitz $160 \mathrm{MV}$, Premiya $190 \mathrm{MV}$, Euro $401 \mathrm{SV}$, Tone $320 \mathrm{VS}$ and pea shoots (Pisum sativum L.) of kinds Deviz, Kharkovsky etalony, Kharkovsky yantarny, Resonator. Treatment of growth regulators emistim $\mathrm{C}$, zeastimulin (for maize), agrostimulin (for pea) and conducted by the seed soakage during 8 hours in its solutions in the concentrations made to order a producer $(0.02 \mathrm{ml} \mathrm{kg}-1$ of seed $)$.

For establishment of cadmium and nickel toxic compatible influence level 2-daily maize and pea shoots maintained 48 hours on solutions of heavy metals in concentrations 3 and $30 \mathrm{mg}$ of $\mathrm{Cd}^{2+} / 1$ and 4 and $40 \mathrm{mg}$ of $\mathrm{Ni}^{2+} / 1$ and then measured the increase of main root and expected a root index (RI) after Wilkins (1978). Study of growth regulators influence on the cadmium and nickel accumulation in the vegetative organs of maize and pea conducted in model experiments with shoots, that grown the water culture method on the distilled water. On 10 day of experiment to the growing environment brought in heavy metals in the concentrations marked higher. Vegetable material was selected for 24 hours after metals bringing. Content of cadmium and nickel was determined on the atomicadsorption spectrophotometer of S-115 (Ukraine) in obedience to the generally accepted methods (Feldman, 1974).

\section{RESULTS AND DISCUSSION}

Research of cadmium and nickel joint action on shoots rootage growth on the initial ontogenesis stages rotined that metals already during a low concentration in an environment result to main root growth braking at all of hybrids and sorts (Table 1). This model experiments analysis allowed dividing the pea sorts by tolerance to cadmium and nickel complex influence on three groups. Most tolerance to stress were pea shoots of sort Kharkovsky yantarny. At the low toxicants level in the growing environment at noted shoots main root length went down on $12 \%$, and at the use of high metals concentration - on $25 \%$, where as at all of other sorts - more than on $30 \%$.

To the joint cadmium and nickel action the shoots of sort Kharkovsky etalony appeared mostsensitive, that is confirmed the lowest values KI both during the low and high toxicants concentration. The sorts of 
Deviz and Resonator were taken to the group moderato sensitive to complex influence metals, because at the low metals concentration root growth inhibition was $21-22 \%$, and at high $31-35 \%$.

Among the maize hybrids the greatest metaltolerance is marked for Blitz $160 \mathrm{MV}$. At joint metals actions in a low concentration the increase of main root went down only on $7 \%$. Most root growth repression under pollutants action was tested by shoots of hybrid Premiya $190 \mathrm{MV}$. At the cadmium and nickel joint action in a minimum concentration registered growth decline on $22 \%$, where as at complex pollutants influence in the maximal concentration RI value was the lowest (Table 1). All of other maize hybrids showed a moderate sensitiveness to the cadmium and nickel compatible action, that is why were taken by us to middle after resistibility to the heavy metals.

It is set as a result of model experiments, that the probed growth regulators for different by resistibility plants demonstrate the unlike directionality of influence (Figure 1). Accordingly, for resistant sort of pea Kharkovsky yantarny prior agrostimulin treatment did not influence on the level of cadmium and nickel compounds tolerance. While emistim $\mathrm{C}$ strengthened the negative metals action.
That is confirmed more intensive root growth inhibition, by comparison to a variant without the growth regulators use. At sorts Resonator and Deviz (middle resistibility) there was a similar tendency. However at sensible sort Kharkovsky etalony previous treatment by the noted regulators determined the substantial increase of shoots metal tolerance (to $85 \%$ ). Thus the protector agrostimulin action showed up brighter than emistim C, especially on a background high maintenance of heavy metals in environment.

In tolerance maize hybrid Blitz $160 \mathrm{MV}$ and middle tolerance Euro $401 \mathrm{SV}$ the protector function of emistim $\mathrm{C}$ in relation to heavy metals was not observed, wherte as zeastimulin caused the increase of shoots metaltolerance on the average on $10 \%$ in both variants.

The protector effect of emistim $\mathrm{C}$ is most expressed marked in the low toxicants concentration at shoots of hybrid Tone $320 \mathrm{VS}$ (tolerance grew on $35 \%$ ). It should be noted that at shoots most sensible to the cadmium and nickel hybrid Premiya 190 MV emistim C neutralized negative influence of metals only in their high concentration, where as previous treatment of zeastimulin resulted in more substantial decline of root grown indexes (on $7-$ $14 \%$ ), than in variants without the use of regulators.

Table 1 .

Main root length $(\mathrm{cm})$ and root indexes $(\mathrm{RI})$ of different pea kind and maize hybrids at joint actions of heavy metals

\begin{tabular}{|c|c|c|c|c|c|}
\hline \multirow{2}{*}{ Test-object } & \multirow{2}{*}{$\begin{array}{l}\text { Control } \\
\mathrm{M} \pm \mathrm{m}\end{array}$} & \multicolumn{2}{|c|}{$3 \mathrm{mg} \mathrm{Cd}^{2+} / 1+4 \mathrm{mg} \mathrm{Ni}^{2+} / 1$} & \multicolumn{2}{|c|}{$30 \mathrm{mg} \mathrm{Cd}^{2+} / 1+40 \mathrm{mg} \mathrm{Ni}^{2+} / 1$} \\
\hline & & $\mathrm{M} \pm \mathrm{m}$ & RI & $\mathrm{M} \pm \mathrm{m}$ & RI \\
\hline Pea sort Resonator & $3.27 \pm 0.08$ & $2.58 \pm 0.09 *$ & 0.79 & $2.25 \pm 0.07 *$ & 0.69 \\
\hline Pea sort Kharkovsky yantarny & $2.58 \pm 0.09$ & $2.27 \pm 0.08^{*}$ & 0.88 & $1.93 \pm 0.06^{*}$ & 0.75 \\
\hline Pea sort Kharkovsky etalony & $2.30 \pm 0.07$ & $1.70 \pm 0.05^{*}$ & 0.74 & $1.28 \pm 0.05^{*}$ & 0.56 \\
\hline Pea sort Deviz & $2.57 \pm 0.06$ & $1.99 \pm 0.07 *$ & 0.78 & $1.67 \pm 0.05^{*}$ & 0.65 \\
\hline Maize hybrid Blitz $160 \mathrm{MV}$ & $2.71 \pm 0.07$ & $2.52 \pm 0.06^{*}$ & 0.93 & $1.67 \pm 0.05^{*}$ & 0.62 \\
\hline Maize hybrid Tone 320 VS & $2.01 \pm 0.06$ & $1.69 \pm 0.05^{*}$ & 0.84 & $1.25 \pm 0.05^{*}$ & 0.62 \\
\hline Maize hybrid Premiya 190 MV & $2.76 \pm 0.06$ & $2.16 \pm 0.06^{*}$ & 0.78 & $1.33 \pm 0.04 *$ & 0.48 \\
\hline Maize hybrid Euro $401 \mathrm{SV}$ & $2.16 \pm 0.06$ & $1.78 \pm 0.05 *$ & 0.82 & $1.27 \pm 0.03 *$ & 0.59 \\
\hline
\end{tabular}

Note: $*$ - statistically a reliable difference is from control at $\mathrm{p}<0.05$.

Figure 1: Influence of growth regulators on shoots main root length for the heavy metals actions ( $\%$ in relation to the experiment variants with heavy metals without regulators application)
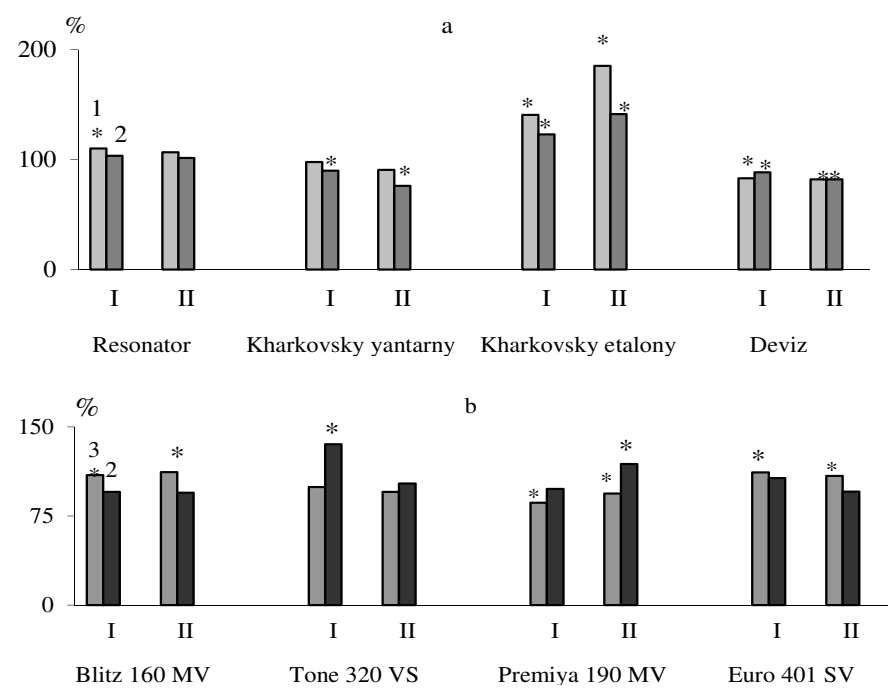

Note: a - pea, b - maize; 1 - agrostimulin, 2 - emistim C, 3 - zeastimulin; I - $3 \mathrm{mg} \mathrm{Cd}^{2+} / 1+4 \mathrm{mg} \mathrm{Ni}^{2+} / 1$, II - $30 \mathrm{mg} \mathrm{Cd}^{2+} / 1+40 \mathrm{mg} \mathrm{Ni}^{2+} / 1 ; *-$ a difference is statistically a reliable difference is in relation to variant without growth regulator at $\mathrm{p}<0.05$. 
As evidently from information, presented in a Figure 2 in the roots of maize plants, treated by zeastimulin, accumulated a cadmium on 45 , and to the nickel on $10 \%$ more than in a variant without application of regulator. The fixed fact can be explained that the regulator stimulates an active transport, the receipt of heavy metals strengthens the same. However previous treatment by zeastimulin was decline of cadmium accumulation level in leaves almost twice and to the nickel - on 15\% (Figure 2). At the discussion of the got results it is necessary to take into account circumstance that intensification of functioning of barrier mechanisms can take a place and due to fastening and compartmentalization of metals ions in a root system. And the growth regulators increase content of sugars, ascorbic acid and other compounds, and thus both straight, and mediated (through influence on the antioxidant systems) reduce the displays of heavy metals negative influence.

The growth regulators from data of Sakalo et al. (2004) can increase content of sugars, ascorbic acid and other compounds, and thus promote the level of physiology adaptation to the heavy metals. By our researchesit is rotined that display of maize plants, which were preliminary treated by zeastimulin on solutions of metals helpful in growth in the roots of ascorbic and 2,3-diketogulonic acids on the average on $25 \%$ (Figure 3). Next to it the dehydroascorbic acid amount did not change by comparison to a variant without a regulator. Analogical growth of vitamin C level under action of agrostimulin is rotined N. Shuvar for Salvia sclarea L. and Calendula officinalis L. (Shuvar et al., 2007).

Figure 2: Influence of growth regulators on the cadmium and nickel ions accumulation in the vegetative organs of maize
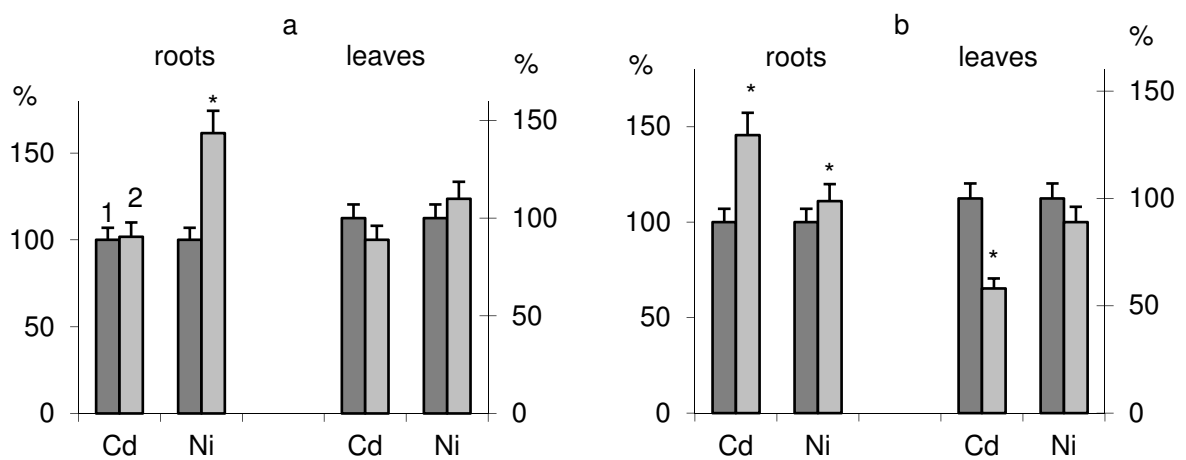

Note: (a) and pea (b) shoots: $1-30 \mathrm{mg} \mathrm{Cd}^{2+} / 1+40 \mathrm{mg} \mathrm{Ni}^{2+} / 1 ; 2-30 \mathrm{mg} \mathrm{Cd}^{2+} / 1+40 \mathrm{mg} \mathrm{Ni}^{2+} / 1+$ growth regulator;* - statistically a reliable difference is in relation to variant without growth regulator at $\mathrm{p}<0.05$

Figure 3: Influence of growth regulators on the cadmium and nickel ions accumulation in the vegetative organs of maize and pea shoots
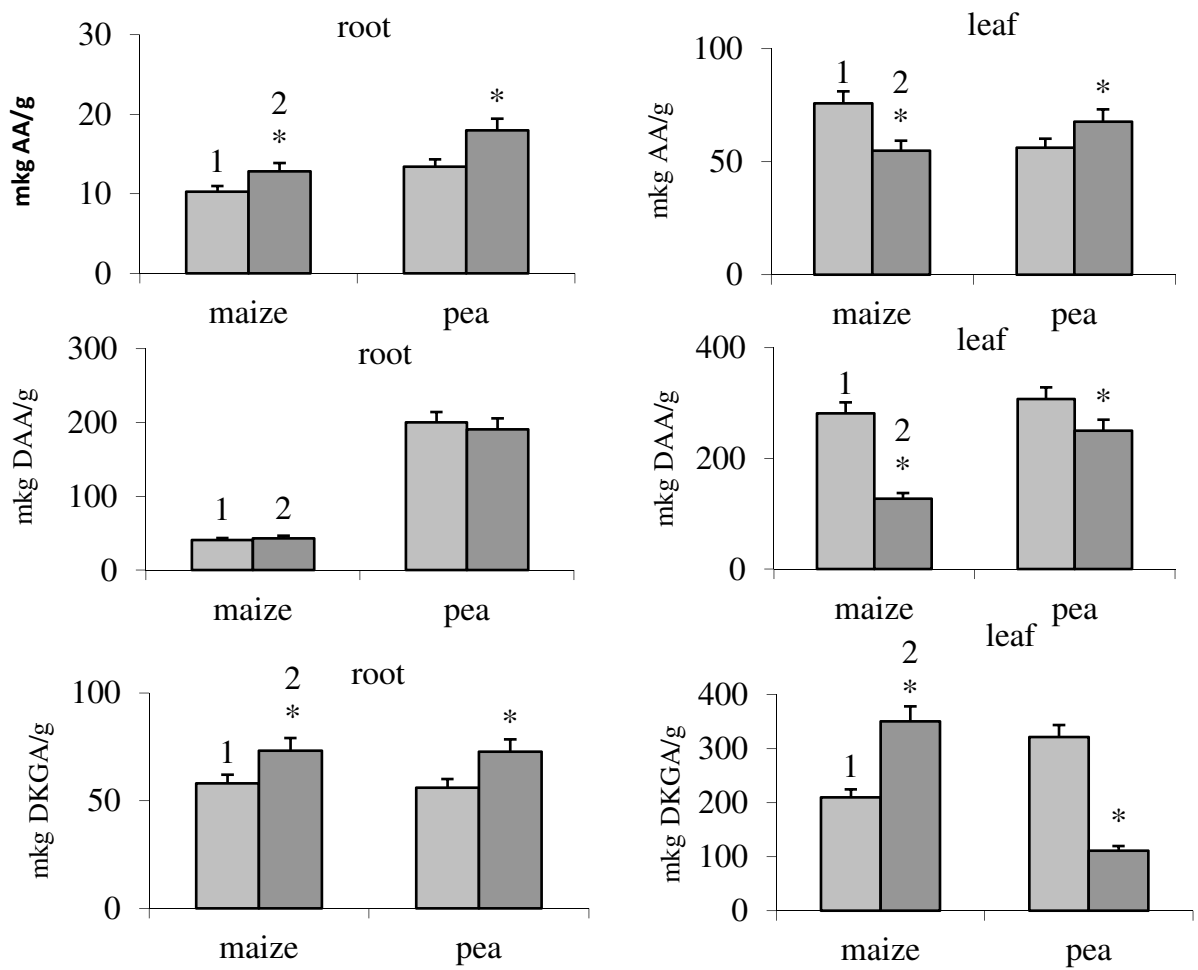

Note: 1 - $30 \mathrm{mg} \mathrm{Cd}^{2+} / 1+40 \mathrm{mg} \mathrm{Ni}^{2+} / 1 ; 2-30 \mathrm{mg} \mathrm{Cd}^{2+} / 1+40 \mathrm{mg} \mathrm{Ni}^{2+} / 1+$ growth regulator; ${ }^{*}$ - statistically a reliable difference is in relation to variant without growth regulator at $\mathrm{p}<0.05, \mathrm{AA}$ - ascorbic acid, DAA - dehydroascorbic acid, DKGA - 2,3-diketogulonic acid. 
However in the maize leaves the zeastimulin use caused the quantity decline of ascorbic and dehydroascorbic acids on 28 and 54\% accordingly, while the level of 2,3-diketogulonic acid was increased on $66 \%$ by comparison to untilled shoots for the cadmium and nickel compounds actions. A decline of ascorbic acid level is in leaves for the actions of metals and growth regulator, except for the utilltaing in the reactions of defuzing of free radicals, also can be caused the outflow of antioxidant from leaves to the roots, as a ascorbic acid biosynthesis at plants takes a place mainly in leaves (Pavet et al., 2005; Pignocchi et al., 2007).

The analysis of these vegetation experiments is conducted rotined that previous treatment of pea seed by agrostimulun had been helpful in the ascorbic acid concentration increase in roots for the heavy metals actions to the control level. Content of dehydroascorbate did not change here, and 2,3-diketogulonic acid - grew, that, probably, testified to activating of antioxidant synthesis processes for the use of growth regulator and more intensive his utilizing in oxidation/reduction reactions.

For the pea leaves similar conformity to the law is set. Application of agrostimulin on a background the joint action of cadmium and nickel compounds was increased of vitamin C level on $20 \%$ by comparison to a variant without a regulator, which arrived at control values however. But, unlike roots, in the pea assimilatory organs the amount of ascorbate oxidized forms went down substantially. The concentration of dehydroascorbic acid for the agrostimulin actions appeared on $20 \%$ below, than without him, while 2,3-diketogulonic acid - almost three times, and was only on $30 \%$ higher than control.

Previous pea seeds treatment by agrostimulin to a certain extent was instrumental in proceeding in a pro/antioxidation balance both in roots and in the pea leaves due to the increase of ascorbic acid concentration and decline of its oxidized forms, probably, by intensification of antioxidant synthesis processes.

\section{CONCLUSIONS}

As a result of bioassay most proof to cadmium and nickel joint influence appeared at a pea - sort Kharkovsky yantarny, at a maize - hybrid Blitz $160 \mathrm{MV}$. As tests-objects more expedient used the pea sort - Kharkovsky etalonny and maize hybrid - Premia 190 MV, as most sensible to the metals joint action. Is set the sorts- and species-specificity of growth regulators action. It is shown that for a maize the most effective protector of cadmium and nickel influence was zeastimulin, for a pea - agrostimulin. A protective function of emistim C for both cultures was insignificant.

It is set that zeastimulin is influential in the increased metals absorption of a root system, however substantially (on $15 \%$ for a nickel and twice for a cadmium) reduces their translocation to above-ground part of plants. Previous treatment of pea seed by agristimulin also intensified the accumulation of nickel roots on $60 \%$ and did not influence on cadmium absorption and toxicants translocation to tissues of assimilatory organs.

The protector role of growth regulators to cadmium and nickel joint influence shows up in the increase of ascorbic acid maintenance in the roots cells of both species to $34 \%$, where as in leaves - at a maize resulted in the lowering of vitamin $\mathrm{C}$ amount (on 28\%), but at a pea - increase on $20 \%$.

\section{ACKNOWLEDGEMENTS}

This study was supported by Hungarian-Ukrainian Intergovernmental S\&T Cooperation Programme for 2009-2010" R\&D bilateral project "Change of soils ecological characteristics of Ukraine and Hungary in the conditions of anthropogenic transformed ecosystems and optimization of biological processes of plants primary feed elements mobilization."

\section{REFERENCES}

Bartoli, C. G.-Tambussi, E. A.-Fanello, D. (2009): Control of ascorbic acid synthesis and accumulation and glutathione by the incident light red/far red ratio in Phaseolus vulgaris leaves. FEBS Letters. 583: $118-122$.

Feldman, C. (1974): Perchloric acid procedure for wetashing organics for the determination of mercury (and other metals). Anal. Chem. 46: $1606-1609$.

Nyzhnyk, T. P.-Grygoryuk, I. P.-Lyholat,D. A. (2004): Dynamics of the intensity of photosynthesis and respiration in potato leaves under drought and protective role of polistymulin K. Physiology and Biocemistry of Cult. Plant. 36. 2: 103-108.

Pavet, V.-Olmos, E-Kiddle, G. (2005): Ascorbic acid deficiency activates cell death and disease resistance responses in Arabidopsis. Plant Physiology. 139: 64-78.

Pignocchi, C.-Kiddle, G.-Hernandez, I. (2007): Ascorbate oxidasedependent changes in the redox state of the apoplast modulate gene transcript accumulation leading to modified hormone signaling and orchestration of defense processes in tobacco. Plant Physiol. 141: 423-435.
Sakalo, V. D.-Ponomarenko, S. P.-Kurchy, V. M. (2004): Effect of processing times treatment by emistim $\mathrm{C}$ and betastimulin on the metabolism of sucrose and productivity of sugar beet. Agrochemicals. 5: 59-65.

Shigeoka, S.-Yoshimura, K.-Ishikawa, T. (2003): Role of ascorbic acid in the protective system of plants against the photooxidation damages. Vitamins. 77. 7: 363-375.

Shuvar, N.-Zakalic, N.-Terek, O. (2007): Vitamins of medicinal herbs for the impact of environmentally friendly growth regulators // Ontogenez of plants in natural and transformed environment. Physiological, biochemical and ecological aspects. Lviv.

Wilkins, D. A. (1978): The measurement of tolerance to edaphic factors by means of root growth. New Phytol. 80. 3: 623-633. 